\title{
Why Study Paleoclimate?
}

\section{U.S. Geological Survey (USGS)} researchers are at the forefront of paleoclimate research, the study of past climates. With their unique skills and perspective, only geologists have the tools necessary to delve into the distant past (long before instrumental records were collected) in order to better understand global environmental conditions that were very different from today's conditions. Paleoclimatologists are geologists who study past climates to answer questions about what the Earth was like in the past and to enable projections, plans, and preparations for the future.

The Intergovernmental Panel on Climate Change (IPCC) has projected a future warmer climate that has the potential to affect every person on Earth. Extreme weather events, rising sea level, and migrating ecosystems and resources could result in worldwide socio-economic stresses if not met with prudent and proactive action plans based on quality
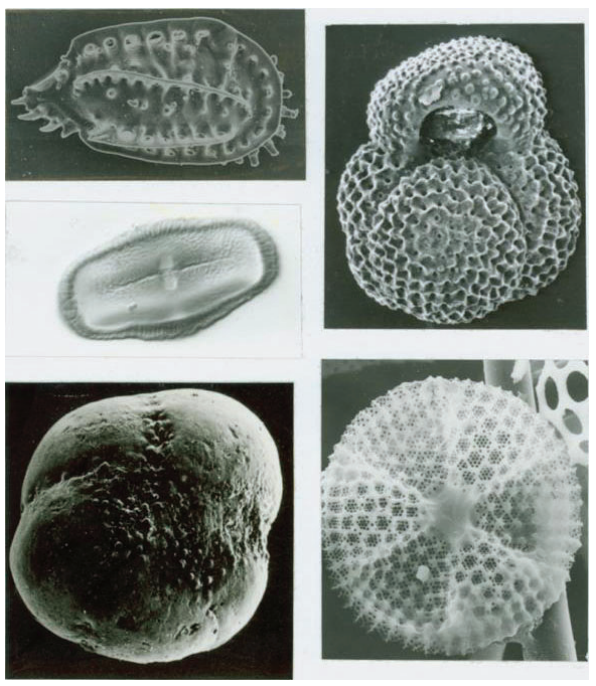

Figure 1. Photomicrographs of examples from microfossil groups used by USGS researchers to study past climates. Clockwise from upper left: ostracode Cativella navis, planktic foraminifer Globigerinoides obliquus, diatom Actinoptychus senarius, benthic foraminifer Ammoelphidiella antarctica, pollen grain of Malabaila pumila (Umbelliferae). scientific research. Still, the most dangerous aspect of our changing climate is the uncertainty in the exact nature and rate of projected climate change.

To reduce the uncertainties, USGS paleoclimatologists are studying a possible analog to a future warmer climate. The middle part of the Piacenzian Stage of the Pliocene Epoch, about 3.3 to 3.0 million years ago, is the most recent period in Earth's history in which global warmth reached and remained at temperatures similar to those projected for the end of this century, about $2^{\circ} \mathrm{C}$ to $3^{\circ} \mathrm{C}$ warmer on average than today over the entire globe. This past warmer time interval preceded the ice ages but was recent enough, geologically, to be very similar to today in terms of ocean circulation and the position of the continents. Also, the populations of plants and animals were much like those of today, and so geologists can use their fossils (fig. 1) to estimate past environmental conditions such as temperature and sea level.

The USGS Pliocene Research, Interpretation and Synoptic Mapping (PRISM) Group has reconstructed global surface and three-dimensional ocean conditions including sea surface temperature, vegetation, sea ice extent, land ice extent, topography, deep ocean temperature, and sea level for the mid-Piacenzian by using fossils and other proxy data (fig. 2, on back). The PRISM digital reconstructions provide boundary conditions for numerical models of climate designed to assess the models' ability to "hindcast" past climates. In theory, accurately reproducing a past climate increases confidence in the models' ability to forecast a future climate.

While paleoclimate studies lead to fewer uncertainties about future climate projections, paleoclimate modeling can also lead to improved reconstructions based on data. That is, unexpected model results often expose intriguing scientific questions that require expanded data coverage or the development of new
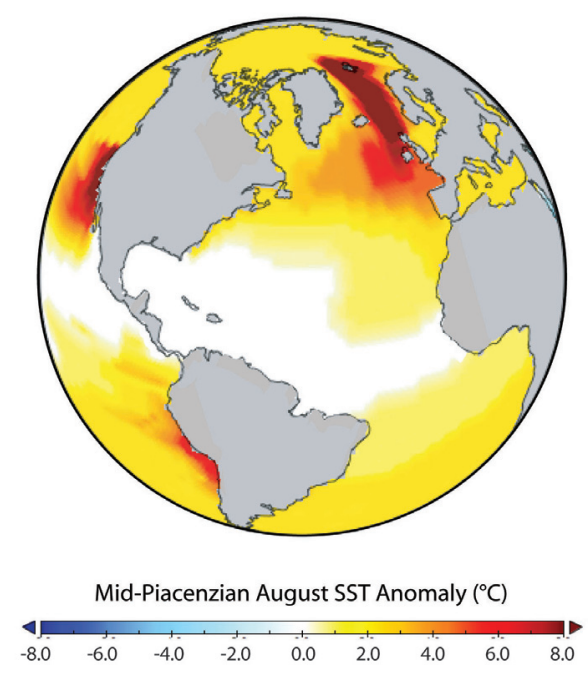

Figure 3. Map of August sea-surfacetemperature (SST) anomalies produced by subtracting modern temperatures from midPiacenzian temperatures. Although there is little temperature difference near the Equator, a large temperature difference exists in the North Atlantic and Arctic Oceans where mid-Piacenzian water was much warmer. The continental outline incorporates a 25 -meter sea-level rise due to the warmer temperatures and lacks glacial features like the Great Lakes that did not exist during the Pliocene.

proxies and provide the impetus for new discoveries.

For example, PRISM data indicate extreme warming of the mid-Piacenzian North Atlantic Ocean and nearby Arctic Ocean (fig. 3). This is where North Atlantic Deep Water formation occurs (when cold salty dense surface water sinks) and drives the global ocean thermohaline circulation. Conventional wisdom states, and model simulations agree, that deep water formation decreases and thermohaline circulation slows when sea surface temperatures are warmer. However, independent studies based on very different lines of evidence show an increase in the formation of North Atlantic Deep Water at this time. Either the mid-Piacenzian climate system in the North Atlantic and Arctic Oceans was very different from 


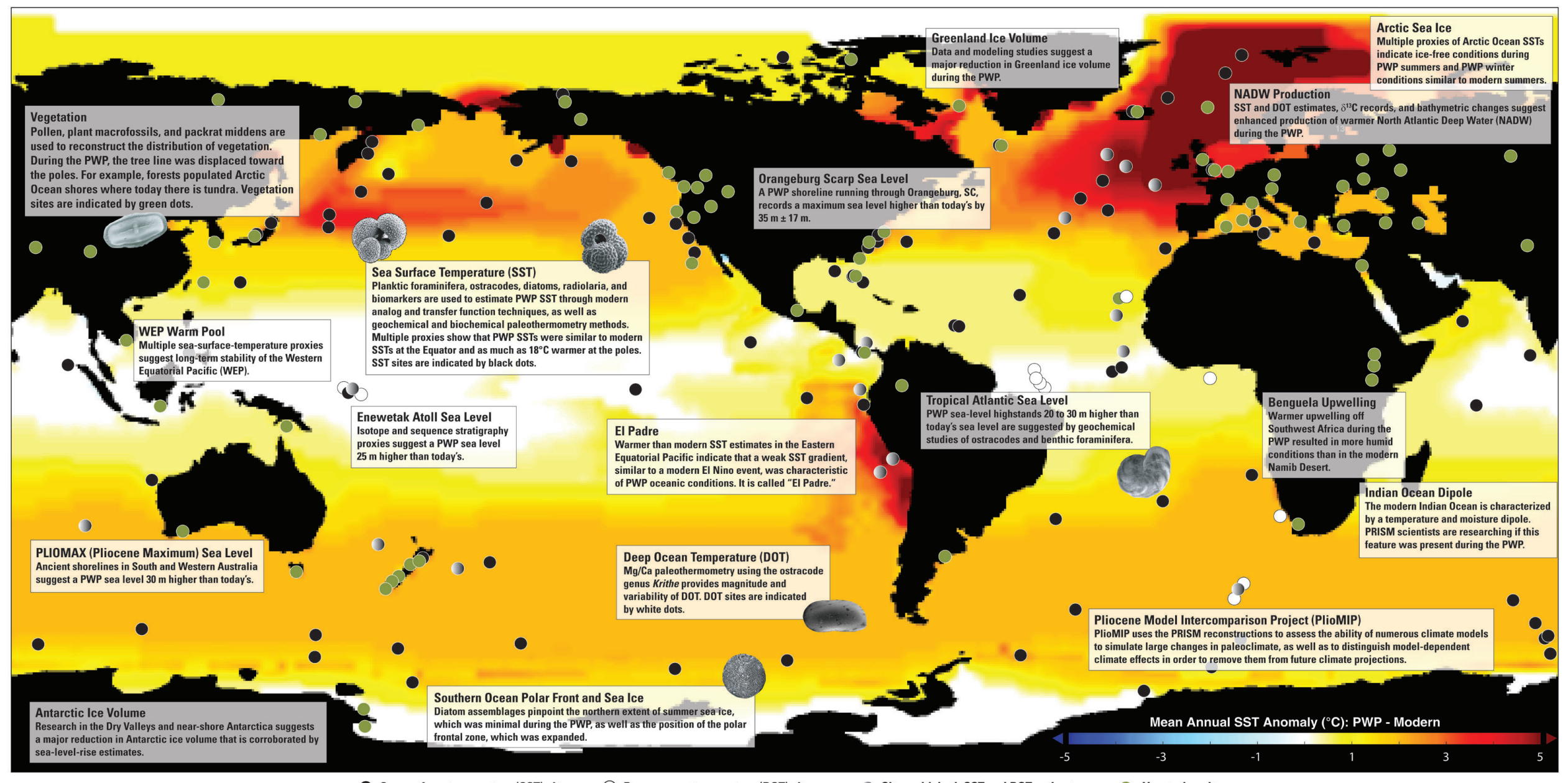

- Sea-surface-temperature (SST) sites $\bigcirc$ Deep-ocean-temperature (D0T) sites

Sites with both SST and DOT estimates

- Vegetation sites

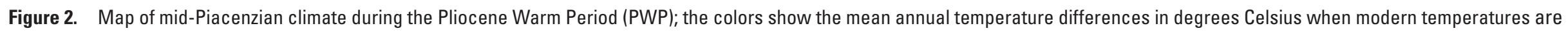

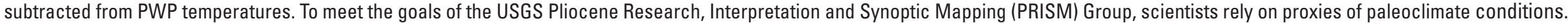
Notes on the map are examples of PRISM findings based on climate proxies.

what our climate will be in the future, or climate models are inadequate in this region and are dramatically underestimating climatic consequences for the Eastern United States and Western Europe. Continued comparisons of paleoclimate data and model simulations are necessary to increase confidence in future climate projections.
In summary, USGS paleoclimatologists are pursuing paleoclimate studies to further our understanding of the past and future warm climates and their impacts. The paleoclimate data collected provide important ground truth for the models and can lead to improved model simulations of future climate.

By Marci Robinson and Harry Dowsett

\section{For more information, please contact:}

Marci Robinson or Harry Dowsett

U.S. Geological Survey

926A National Center

Reston, VA 20192

Telephone: 703-648-5291/5282

Fax: 703-648-6953

Email:mmrobinson@usgs.gov or hdowsett@usgs.gov

Web: http://geology.er.usgs.gov/eespteam/prism/index.html 